\title{
Effect of Chronic Administration of Aqueous Leaves Extract of Moringa Stenopetala on Blood Parameters and Histology of Liver and Kidney in Rats
}

\author{
Fikre Bayu ${ }^{1}$, Mekbeb Afework ${ }^{1 *}$, Bekesho Geleta ${ }^{2}$, Wondwossen Ergete ${ }^{3}$, Eyasu \\ Makonnen ${ }^{4}$
}

\footnotetext{
OPEN ACCESS

Citation: Fikre Bayu, Mekbeb Afework, Bekesho Geleta, Wondwossen Ergete, Eyasu Makonnen. Effect of Chronic Administration of Aqueous Leaves Extract of Moringa Stenopetala on Blood Parameters and Histology of Liver and Kidney in Rats. Ethiop J HealthSci.2020;30(2):259.

doi:http://dx.doi.org/10.4314/ejhs.v30 i2.14

Received: October 07, 2019

Accepted: November 11, 2019

Published: March 1, 2020

Copyright: (C2020 Fikre Bayu, et al. This is an open access article distributed under the terms of the Creative Commons Attribution License, which permits unrestricted use, distribution, and reproduction in any medium, provided the original author and source are credited.

Funding: This study was funded by Addis Ababa University.

Competing Interests: The authors declare that this manuscript was approved by all authors in its form and that no competing interest exists.

Affiliation and Correspondence:

${ }^{1}$ Department of Anatomy, School

of Medicine, College of Health

Sciences, Addis Ababa

University, Ethiopia.

${ }^{2}$ Ethiopian Public Health Institute, Traditional and Modern Medicine Drug Department, Addis Ababa, Ethiopia ${ }^{3}$ Department of Pathology, School of Medicine, College of Health Sciences, Addis Ababa University, Addis Ababa, Ethiopia

${ }^{4}$ Department of Pharmacology, School of Medicine, College of Health Sciences, Addis Ababa University,Addis Ababa, Ethiopia

*Email: m.afework@yahoo.com
}

\begin{abstract}
BACKGROUND: Moringa stenopetala is used as nourishments, and treatment of various diseases. However, there is no much information on its safety. Hence, this study aimed to investigate the chronic administration of aqueous leaves extract of the plant.

MATERIALS AND METHODS: Twenty-four rats were divided into: a control group administered with distilled water and three experimental groups, respectively, administered with the extract at doses of 500, 1000, and $2000 \mathrm{mg} / \mathrm{kg}$ orally for six months were investigated. Various hematological and biochemical parameters followed by histopathological analysis were evaluated.

RESULTS: Treatment with the extract did not significantly affect most of the hematological parameters. However, there were a significant decrease of $\mathrm{MCH}$ at doses of $1000 \mathrm{mg} / \mathrm{kg}$ and 2000 $\mathrm{mg} / \mathrm{kg}$ in male rats and increase of MCV at all doses in female rats. Levels of ALP at $2000 \mathrm{mg} / \mathrm{kg}$ and those of AST and ALT at 1000 and $2000 \mathrm{mg} / \mathrm{kg}$ were significantly increased in male rats. Furthermore, significant decrease in urea and increase in creatinine levels at the dose of $2000 \mathrm{mg} / \mathrm{kg}$ occurred in female rats. Mild histopathological changes were also observed in the liver of male rats and kidney of female rats treated with the extract, respectively at doses of 1000 and $2000 \mathrm{mg} / \mathrm{kg}$, and $2000 \mathrm{mg} / \mathrm{kg}$.

CONCLUSION: Findings from the present study suggest that prolonged administration of extract of Moringa stenopetala at therapeutic doses is safe, but shows sign of mild toxicity as dose increases, with differential effect on male verses female rats.

KEYWORDS: rats, Moringa stenopetala, chronic toxicity, histology of liver, histology of kidney, hematological parameters, biochemical parameters
\end{abstract}




\section{INTRODUCTION}

Plants have traditionally been used for treatment and prevention of human and animal diseases. The major limitation of traditional medicine is, however, that there are no many records and information regarding their safety and toxicity.

One of such plant species widely used is Moringa stenopetala, which belongs to the family Moringaceae. It is a branched tree with multipennate leaves that grows 6 to $10 \mathrm{~m}$ tall (1) at an altitude ranging between 1000 and $1800 \mathrm{~m}$ above sea level. The plant is endemic to East Africa, mainly found in Northern Kenya and southern part of Ethiopia (2,3). It grows abundantly in southwest part of Ethiopia where the leaves, which have high nutritional as well as medicinal value, are eaten as vegetable (1).

Moringa species have been used to combat malnutrition, especially among infants and nursing mothers. Leaves can be eaten fresh, cooked, or stored as dried powder for many months without refrigeration and loss of nutritional value. Medicinally, almost all parts of this plant have been used for treating various ailments (4). Furthermore, its leaves act as a good source of natural antioxidant due to the presence of various types of antioxidant compounds (5).

Laboratory based studies on different animal models have also suggested for medicinal and nutritional values of the plant. A significant drop in mean arterial blood pressure was reported following administration of $M$. stenopetala in guinea pigs (6). Furthermore, leaf extract of $M$. stenopetala were reported by several authors to increase body weight and reduce serum glucose and cholesterol levels in mice and rats (7-9). Because of such diverse values of $M$. stenopetala, currently, there is an increasing promotion and utilizations of the plant for various purposes. However, this may call for adequate investigation and proper documentation of its safety and toxicity. On the contrary, there are only limited studies that investigated the safety and toxicity of $M$. stenopetala aqueous leaf extract as most of the studies conducted so far are either nutritional analyses or efficacy tests in laboratory animals. Furthermore, the studies which addressed safety of the plant are related to acute and/or sub-chronic investigation, and so far, there is no study carried out on chronic toxicity of M. stenopetala on blood parameters and histopathology of liver and kidney. Such a chronic study, which assesses the safety of the plant may be needed as it is normally consumed for a prolonged period of time for nutritional, therapeutic as well as preventive purposes. The present study is, therefore, aimed to investigate if there is any effect on blood parameters as well as histopathology of liver and kidney following administration of the extract for six months in Wistar rats.

\section{MATERIALS AND METHODS}

The study was conducted at Traditional and Modern Medicine Research Directorate of Ethiopian Public Health Institute and Department of Anatomy, College of Health Sciences, Addis Ababa University.

Collection and extraction of plant materials: Fresh leaves of $M$. stenopetala were collected from Arba Minch, $502 \mathrm{~km}$ southwest from Addis Ababa. The leaves were identified and authenticated by a taxonomist, and a voucher number MS-01-2016 was deposited in the herbarium. Fresh leaves were cleaned, dried under shade at room temperature, and ground by manual crusher (10). The powdered leaves were macerated with distilled water for $4 \mathrm{hrs}$ with intermittent agitation by orbital shaker. The supernatant was separated from the un-dissolved portion, and was filtered with $0.1 \mathrm{~mm}^{2}$ mesh gauze and whatman filter paper. The filtrate was freezedried at low temperature $\left(-46^{\circ} \mathrm{C}-51^{\circ} \mathrm{C}\right)$ and low pressure $\left(133 \times 10^{-3} \mathrm{mbr}\right)$ to form crude extract and was kept in desiccators at room temperature until used (10).

Selection and preparation of experimental animals: Both sexes of adult Wistar rats (8-12 weeks old) obtained from Ethiopian Public Health Institute were used for the study. Females were nulliparous and non-pregnant. Rats were randomly grouped into experimental and control groups, and were kept under standard conditions (temperature of $22^{\circ} \mathrm{C}\left( \pm 3^{\circ} \mathrm{C}\right)$, relative humidity of $50-60 \%$, with $12 \mathrm{~h}$ light $/ 12 \mathrm{~h}$ dark cycle) (11). For feeding, conventional rodent laboratory diets were used with water Ad libitum.

Toxicity studies on experimental animals were carried out in compliance with general guidelines

DOI: http://dx.doi.org/10.4314/ejhs.v30i2.14 
on methodologies on research and evaluation of traditional medicine promulgated by WHO (12). The experimental design involving the mice for the study was also as per the guidelines for carrying research on animals (13).

Method of extract administration: The extract and distilled water were given orally using intragastric catheter. Following a period of fasting, the animals were weighed weekly, and the dose was calculated according to the body weight, and administered each day (14).

Chronic toxicity study: The study was carried out using 24 rats randomly assigned into four groups: one control and three experimental groups (groups I-III), each containing 6 rats (three males and three females). Rats in groups I, II and III received the extract of M. stenopetala at doses of 500, 1000, and $2000 \mathrm{mg} / \mathrm{kg}$ body weight, respectively, daily for six months.

Cage side observation: Treated rats were observed daily for any general sign of abnormalities during the whole study period.

Body weight measurement: Body weights of all animals were recorded using digital electronic balance sensitive to $0.001 \mathrm{gm}$ (Precisa 125A, Switzerland) before the first oral administration, and then weekly until the last day of administration.

Blood samples collection: At the end of the experiment, animals were made to fast overnight, and sacrificed by cervical dislocation. Blood samples were then collected into sterile tube by cardiac puncture. Parts of the blood samples were put in separate test tubes with and without EDTA.

Hematological parameters including white blood cells (WBCs) and its differentials, red blood cells (RBCs), hemoglobin (HGB), hematocrit (HCT), mean corpuscular volume (MCV), mean corpuscular hemoglobin $(\mathrm{MCH})$, mean corpuscular hemoglobin concentration (MCHC) and platelets were analyzed immediately from the blood samples collected with EDTA using Automated Hematological Analyzer (SYSMEX RX 21, Japan). For biochemical analysis, blood samples collected without EDTA were allowed to stand for $2 \mathrm{hrs}$ for complete clotting and centrifuged at $5000 \mathrm{rpm}$ for 10 minutes using a bench top centrifuge (HUMAN-
$\mathrm{GmbH}$, Germany). Serum from each sample was withdrawn through micropipette and transferred into other clean vial tubes which were kept at $-20^{\circ} \mathrm{C}$ until analysis. Subsequently, concentrations of ALP, ALT, AST, total Bilirubin, Urea and Creatinine were determined using Clinical Chemistry Analyzer, Italy.

Organs weight measurements and tissue processing: Liver and kidneys were dissected and weighed with precision electronic digital balance. Sample tissues from liver and left kidney were collected randomly and fixed in $10 \%$ buffered formalin. These were dehydrated and cleared in ascending graded series of ethanol and xylene, infiltrated with molten paraffin wax and embedded in paraffin blocks. Tissue sections were cut at $5 \mu \mathrm{m}$ thickness and fixed onto clean frosted slide glasses and were stained with hematoxylin and eosin (H\&E). Finally, the prepared slides were examined under Binocular compound light microscope for any possible histopathological findings and were photographed under X400 total magnification using Photomicrograph (Leica ICC50, China).

Data processing and analysis: All data obtained from the experiments were entered and analyzed statistically on SPSS 21 version software and presented as mean \pm standard error of the mean (SEM). The difference between treatment and control groups were compared using one-way analysis of variance (ANOVA). This was followed by analysis with Dunnett's post hoc test which compares the means from several experimental groups against that of a control. Differences between the various groups were considered statistically significant at $\mathrm{P}<0.05$.

\section{RESULTS}

No sign of toxicity was observed in rats treated with the extract, except for those which received the extract at doses of $2000 \mathrm{mg} / \mathrm{kg}$ body weight which showed low locomotion, weakness, dizziness, shivering and piloerection during the first and second weeks of administration in both sexes. Moreover, there was no morbidity and death throughout the study period.

There were progressive body weight gains in all groups of rats of both sexes over the whole period

DOI: http://dx.doi.org/10.4314/ejhs.v30i2.14 
of the experiment. However, there were transitional significant body weight decrements during $1^{\text {st }}$ and $2^{\text {nd }}$ weeks (for the male) and $1^{\text {st }}-3^{\text {rd }}$ weeks (for the female, Figure 1) rats treated with the extract at dose of $2000 \mathrm{mg} / \mathrm{kg}$.
No significant difference was observed in the pattern of body weight gain among the different groups of rats in both experimental groups and controls.

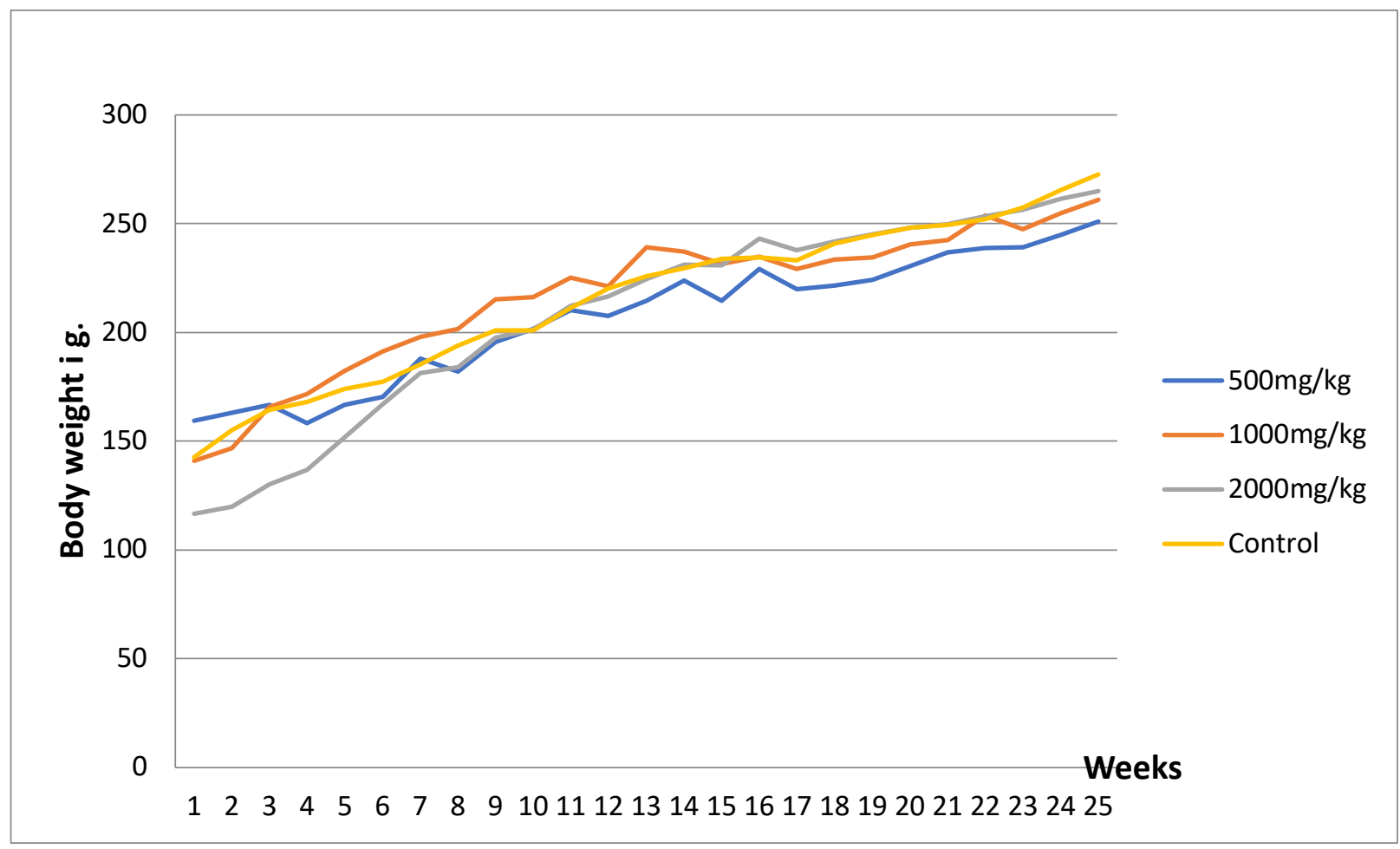

Figure 1: Mean body weight (gram) of female rats administered with 500, 1000 and $2000 \mathrm{mg} / \mathrm{kg}$ of the extract during the consecutive 24 weeks of measurement compared to the controls

Effect of $M$. stenopetala aqueous leaves extract on hematological parameters: The effect of 24 weeks oral administration of $M$. stenopetala on hematological parameters of the rats is illustrated in Table 1. Chronic administration of the extracts did not significantly affect the large majorities of the hematological parameters, except for the $\mathrm{MCH}$ and MCV. There was a significant decrement of in $\mathrm{MCH}$ in male rats at doses of $1000 \mathrm{mg} / \mathrm{kg}$ and 2000 $\mathrm{mg} / \mathrm{kg}$ as compared to their control counterparts. In addition, the extract induced significant elevation $\mathrm{MCV}$ of female rats at all doses.

Effect $M$. stenopetala aqueous leaves extract on biochemical parameters: Effects of chronic oral treatment with aqueous leaves extract of $M$. stenopetala on serum biochemical parameters of rats are shown in Table 2. Most of the biochemical markers were not affected in the extract treated rats as compared to the controls. However, in the male rats treated with the extract, significant increases were observed in the ALP at dose of $2000 \mathrm{mg} / \mathrm{kg}$, and AST and ALT at doses of 1000 and 2000 $\mathrm{mg} / \mathrm{kg}$. Furthermore, female rats administered with the extract at the dose of $2000 \mathrm{mg} / \mathrm{kg}$ showed significant decrement and increment in urea and creatinine levels, respectively. 
Table 1: Effects of chronic administration of $500 \mathrm{mg} / \mathrm{kg}, 1000 \mathrm{mg} / \mathrm{kg}$ and $2000 \mathrm{mg} / \mathrm{kg}$ aqueous leaf extract of $M$. stenopetala on hematological parameters in male (M) and female $(\mathrm{F})$ rats as compared to the controls

\begin{tabular}{|c|c|c|c|c|c|c|c|c|}
\hline \multirow{2}{*}{$\begin{array}{c}\text { Hematological } \\
\text { parameters }\end{array}$} & \multicolumn{2}{|c|}{$500 \mathrm{mg} / \mathrm{kg}$} & \multicolumn{2}{|c|}{$1000 \mathrm{mg} / \mathrm{kg}$} & \multicolumn{2}{|c|}{$2000 \mathrm{mg} / \mathrm{kg}$} & \multicolumn{2}{|c|}{ Control } \\
\hline & M & $\mathbf{F}$ & $\mathbf{M}$ & $\mathbf{F}$ & $\mathbf{M}$ & $\mathbf{F}$ & $\mathbf{M}$ & $\mathbf{F}$ \\
\hline WBC(x $\left.10^{3} / \mu \mathrm{L}\right)$ & $8.7 \pm 3.14(.890)$ & $5.10 \pm 1.36(.967)$ & $6.3 \pm 0.67(.992)$ & $8.49 \pm 0.86(.110)$ & $6.3 \pm 1.01(.991)$ & $4.18 \pm 1.43(.996)$ & $6.99 \pm 0.50$ & $4.48 \pm 1.11$ \\
\hline $\operatorname{NEUT}\left(\times 10^{3} / \mu \mathrm{L}\right)$ & $1.09 \pm 0.18(.558)$ & $0.40 \pm 0.08(.339)$ & $1.14 \pm 0.26(.445)$ & $0.84 \pm 0.12(.965)$ & $0.96 \pm 0.03(.850)$ & $0.71 \pm 0.38(.813)$ & $0.78 \pm 0.07$ & $0.98 \pm 0.35$ \\
\hline $\begin{array}{c}\text { LYMPH(x } \\
\left.10^{3} / \mu \mathrm{L}\right)\end{array}$ & $6.96 \pm 2.62(.930)$ & $4.48 \pm 1.29(.576)$ & $4.41 \pm 0.79(.919)$ & $6.05 \pm 0.92(.131)$ & $4.89 \pm 0.89(.977)$ & $3.09 \pm 1.05(.999)$ & $5.72 \pm 0.61$ & $5.72 \pm 0.61$ \\
\hline $\begin{array}{c}\text { MONO(x } \\
\left.10^{3} / \mu \mathrm{L}\right)\end{array}$ & $0.57 \pm 0.24(.709)$ & $0.23 \pm 0.03(.705)$ & $0.60 \pm 0.08(.605)$ & $0.60 \pm 0.29(.381)$ & $0.38 \pm 0.11(.999)$ & $0.27 \pm 0.05(.867)$ & $0.35 \pm 0.04$ & $0.37 \pm 0.13$ \\
\hline $\operatorname{EO}\left(\times 10^{3} / \mu \mathrm{L}\right)$ & $0.17 \pm 0.04(.792)$ & $0.12 \pm 0.01(.781)$ & $0.15 \pm 0.05(.911)$ & $0.19 \pm 0.02(.541)$ & $0.03 \pm 0.01(.614)$ & $0.09 \pm 0.04(.567)$ & $0.11 \pm 0.61$ & $0.18 \pm 0.10$ \\
\hline $\operatorname{BASO}\left(\times 10^{3} / \mu \mathrm{L}\right)$ & $0.05 \pm 0.01(.898)$ & $0.06 \pm 0.01(.732)$ & $0.03 \pm 0.01(.952)$ & $0.01 \pm 0.06(.299)$ & $0.04 \pm 0.03(1.000)$ & $0.02 \pm 0.003(.998)$ & $0.04 \pm 0.01$ & $0.02 \pm 0.01$ \\
\hline $\operatorname{RBC}(\times 106 / \mu \mathrm{L})$ & $10.01 \pm 0.57(0.603)$ & $8.03 \pm 0.33(0.955)$ & $9.09 \pm 0.88(1.000)$ & $8.73 \pm 0.35(1.000)$ & $10.03 \pm 0.22(.613)$ & $7.21 \pm 1.62(.685)$ & $9.07 \pm 0.17$ & $8.66 \pm 1.38$ \\
\hline $\operatorname{HGB}(\mathrm{g} / \mathrm{dl})$ & $18.5 \pm 0.85(.819)$ & $15.7 \pm 0.72(.928)$ & $16.23 \pm 1.78(.898)$ & $16.53 \pm 0.48(.997)$ & $18.4 \pm 0.42(.851)$ & $15.67 \pm 0.81(.918)$ & $17.23 \pm 0.37$ & $16.33 \pm 1.41$ \\
\hline HCT (\%) & $57.57 \pm 2.92(.428)$ & $47.47 \pm 2.24(.989)$ & $50.27 \pm 4.21(.989)$ & $52.23 \pm 2.13(.754)$ & $56.23 \pm 1.45(.613)$ & $41.47 \pm 8.62(.922)$ & $51.43 \pm 0.95$ & $45.5 \pm 6.77$ \\
\hline $\operatorname{MCV}(f L)$ & $57.33 \pm 0.54(.945)$ & $59.10 \pm 0.79(.010)^{*}$ & $55.47 \pm 1.39(.669)$ & $59.77 \pm 1.13(.006)^{*}$ & $56.03 \pm 0.44(.917)$ & $58.20 \pm 1.60(.023)^{*}$ & $56.73 \pm 0.03$ & $52.77 \pm 0.74$ \\
\hline MCH(pg) & $18.47 \pm 0.23(.259)$ & $19.53 \pm 0.27(1.000)$ & $17.83 \pm 0.27(.010) *$ & $18.97 \pm 0.20(.999)$ & $17.89 \pm 0.07(.011)^{*}$ & $24.33 \pm 5.79(.562)$ & $19 \pm 0.10$ & $19.47 \pm 1.84$ \\
\hline $\operatorname{MCHC}(g / d L)$ & $32.17 \pm 0.39(.479)$ & $33.07 \pm 0.07(.889)$ & $32.13 \pm 1.17(.460)$ & $31.77 \pm 0.52(.779)$ & $32.73 \pm 0.15(.823)$ & $41.3 \pm 8.55(.821)$ & $33.5 \pm 0.20$ & $36.77 \pm 2.89$ \\
\hline $\operatorname{PLC}\left(\times 10^{3} / \mu \mathrm{L}\right)$ & $339.67 \pm 229.7(.553)$ & $120 \pm 31.34(.703)$ & $351.67 \pm 208.9(.580)$ & $590 \pm 113.66(.125)$ & $720.3 \pm 93.2(.996)$ & $256 \pm 139.4(1.000)$ & $669.3 \pm 110.1$ & $254.67 \pm 103.89$ \\
\hline
\end{tabular}

Data are expressed as mean $\pm \mathrm{SEM}, \mathrm{N}=3$. The figures under brackets indicate the $\mathrm{P}$-values, $\mathrm{N}=$ Number of rats per group; ${ }^{*}=\operatorname{significant}(\mathrm{P}<0.05)$. 
Table 2: Effect of 500, 1000 and $2000 \mathrm{mg} / \mathrm{kg}$ aqueous leaves extract of $M$. stenopetala on biochemical parameters of male (M) and female (F) rats compared to the control group

\begin{tabular}{|c|c|c|c|c|c|c|c|c|}
\hline \multirow{2}{*}{$\begin{array}{l}\text { Biochemical } \\
\text { parameters }\end{array}$} & \multicolumn{2}{|c|}{$500 \mathrm{mg} / \mathrm{kg}$} & \multicolumn{2}{|c|}{$1000 \mathrm{mg} / \mathrm{kg}$} & \multicolumn{2}{|c|}{$2000 \mathrm{mg} / \mathrm{kg}$} & \multicolumn{2}{|c|}{ Control } \\
\hline & $\mathbf{M}$ & $\mathbf{F}$ & $\mathbf{M}$ & $\mathbf{F}$ & $\mathbf{M}$ & $\mathbf{F}$ & M & $\mathbf{F}$ \\
\hline ALP (IU/L) & $109.33 \pm 8.65(.057)$ & $84 \pm 22.05(.538)$ & $109.67 \pm 16.76(.056)$ & $79.33 \pm 6.64(.475)$ & $119.67 \pm 21.67(.030)^{*}$ & $144 \pm 49.52(.989)$ & $44.33 \pm 16.17$ & $133 \pm 24.7$ \\
\hline ALT (IU/L) & $122.47 \pm 36.46(.187)$ & $175 \pm 54.17(.980)$ & $149.27 \pm 33.10(.03 *$ & $96.33 \pm 14.78(.367)$ & $136.07 \pm 42.74(.042)^{*}$ & $93.43 \pm 12.41(.337)$ & $88.73 \pm 14.56$ & $161.73 \pm 23.16$ \\
\hline AST (IU/L) & $274.67 \pm 97.95(.157)$ & $712.2 \pm 204.09(.438)$ & $521 \pm 57.27(.032)^{*}$ & $396.53 \pm 129.72(.990)$ & $316.03 \pm 103.60(.048)^{*}$ & $274.6 \pm 109.2(.733)$ & $196.9 \pm 48.54$ & $444.57 \pm 90.97$ \\
\hline Urea $(\mathrm{g} / \mathrm{dl})$ & $46.5 \pm 1.21(.879)$ & $40.43 \pm 2.71(.075)$ & $49.67 \pm 2.48(.303)$ & $39.87 \pm 3.58(.062)$ & $38.67 \pm 0.45(.193)$ & $38.9 \pm 1.99(.044)^{*}$ & $44.67 \pm 3.30$ & $51.53 \pm 3.49$ \\
\hline $\begin{array}{c}\text { Creatinine } \\
(\mathrm{mg} / \mathrm{dl})\end{array}$ & $0.33 \pm 0.05(.668)$ & $0.19 \pm 0.02(.997)$ & $0.24 \pm 0.03(.787)$ & $0.26 \pm 0.03(.397)$ & $0.28 \pm 0.01(.998)$ & $0.34 \pm 0.02(0.023)^{*}$ & $0.28 \pm 0.03$ & $0.2 \pm 0.05$ \\
\hline $\begin{array}{l}\text { Bilirubin } \\
\text { (mg/dl) }\end{array}$ & $4.59 \pm 0.14(.994)$ & $4.56 \pm 0.52(.887)$ & $4.09 \pm 0.15(.184)$ & $4.29 \pm 0.56(.999)$ & $4.53 \pm 0.03(.810)$ & $4.53 \pm 0.38(.922)$ & $4.79 \pm 0.45$ & $4.34 \pm 0.120$ \\
\hline
\end{tabular}

Data are expressed as mean $\pm \mathrm{SEM}, \mathrm{N}=3$. The figures under brackets indicate the $\mathrm{P}$-values, $\mathrm{N}=\mathrm{Number}$ of rats per group; ${ }^{*}=$ significant $(\mathrm{P}<0.05)$.

Effect of M. stenopetala aqueous leaves extract on histology of the liver: Histological examination of liver sections of male rats treated with the extract at a dose of $500 \mathrm{mg} / \mathrm{kg}$ body weight and female rats treated at all doses had normal architecture similar to the controls (Figure 2A, 2B). However, male rats treated with the extract at doses of $1000 \mathrm{mg} / \mathrm{kg}$ (Figure 2C, 2D) and 2000 $\mathrm{mg} / \mathrm{kg}$ (Figure 2E, 2F) showed signs of bile retention which suggested for induction of cholestasis (biliary stasis). These were observed as yellowish discoloring of hepatocytes and deposits in the bile canaliculi between the individual hepatocytes. Moreover, around the central veins and portal triads, there were mononuclear leukocytic cells infiltration (Figure 2E, 2F), congestion of sinusoids, cytoplasmic vacuolization and hydropic changes (Figure 1E, 1F), revealing mild hepatotoxicity. 

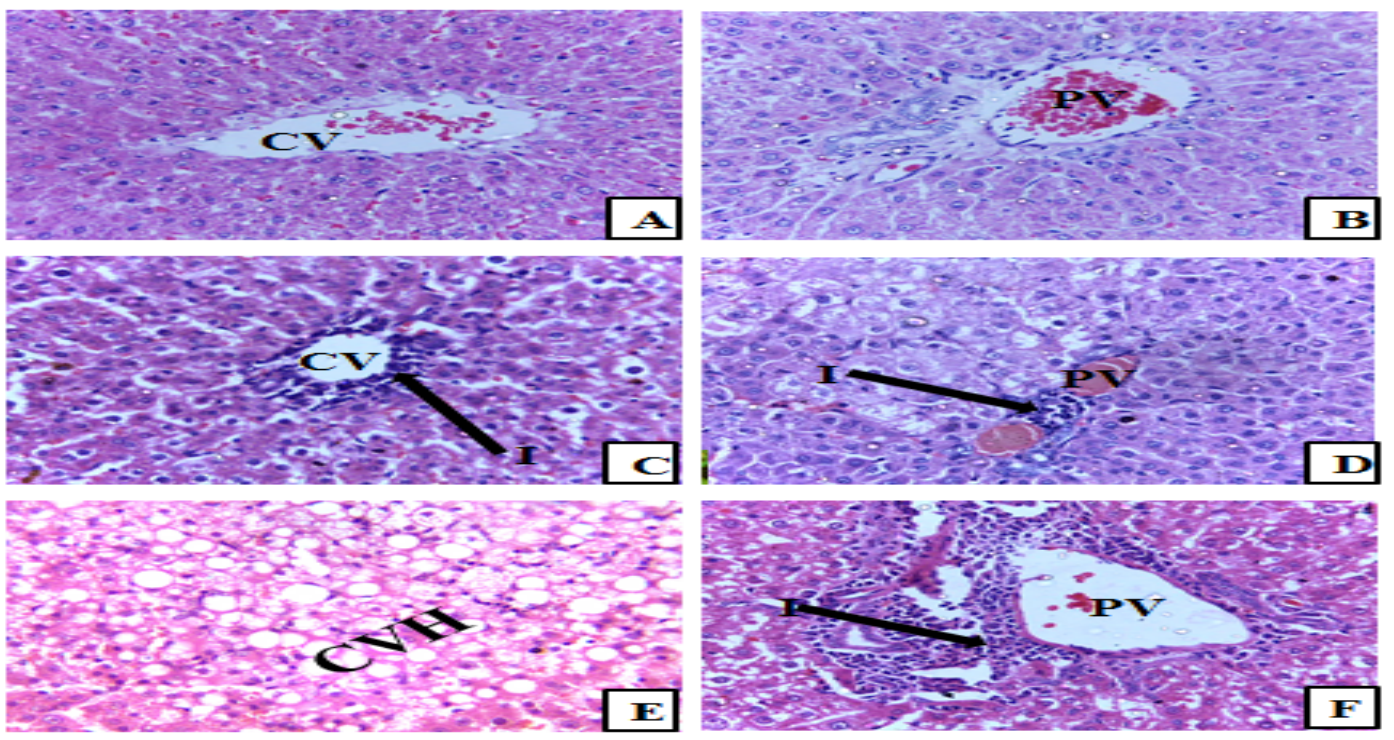

Figure 2: Photomicrographs $H$ and $E$ stained sections of liver of male rats treated with the aqueous leaves extract of M. stenopetala with $1000 \mathrm{mg} / \mathrm{kg}(C \& D)$ and $2000 \mathrm{mg} / \mathrm{kg}(E \& F)$ as compared to the controls (A\&B). Note: Cytoplasmic vacuolization of hepatocytes (CVH) and mononuclear leukocytic infiltrations (I) at 1000 and $2000 \mathrm{mg} / \mathrm{kg}$; $C V=$ Central vein, $P V=$ Portal vein; all slides were at $X 400$

\section{Effect of M. stenopetala aqueous leaves extract on histology of the kidney: Histological} evaluation of kidney sections of treated rats showed some histopathological changes only in the female rats treated with the extract at a dose of $2000 \mathrm{mg} / \mathrm{kg}$. These were observed as minor tubulointerstitial leukocytic infiltrations in some areas of cortex and medulla. In addition,
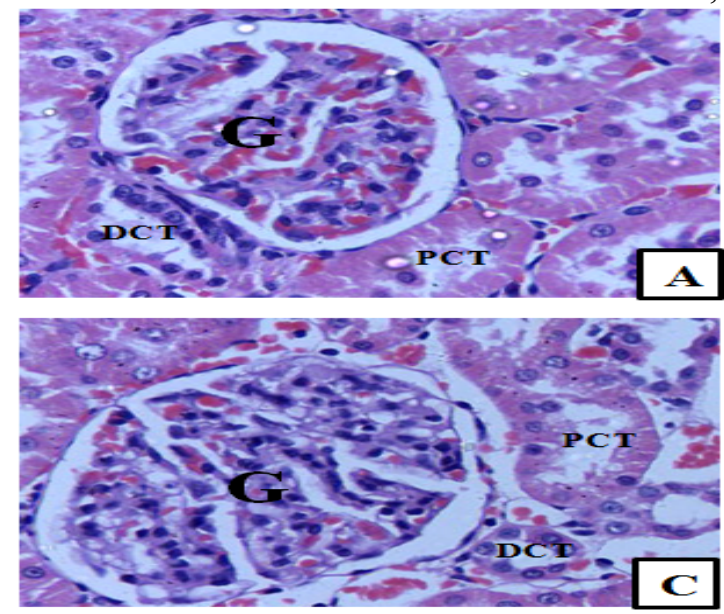

widening of the urinary space and congestion of glomeruli in some of the renal corpuscles were apparent. On the other hand, no change was observed in the female rats treated with the extract at doses of 500 and $1000 \mathrm{mg} / \mathrm{kg}$, as well as male rats treated at all doses as compared to the controls (Figure 3).

Figure 3: Photomicrographs $H$ and $E$ stained sections of kidney of female rats treated with the aqueous leaves extract of M. stenopetala with $2000 \mathrm{mg} / \mathrm{kg}$ (C and D) as compared to the controls $(A \& B)$. Note: Widened urinary space and minor tubulointerstitial infiltrations (I) $G=$ Glomerulus, $P C T=$ proximal convoluted tubule, $D C T=$ distal convoluted tubule, OMR= outer medullary region and IMR = inner medullary region; all slides were at $400 X$.

DOI: http://dx.doi.org/10.4314/ejhs.v30i2.14 


\section{DISCUSSION}

The results of 24 weeks chronic treatment of the aqueous leaves extract of $M$. stenopetala showed that the extract was well tolerated by all rats. The mild sign of toxicity observed in rats treated with the extract at the dose of $2000 \mathrm{mg} / \mathrm{kg}$ body weight may be due to a transient nervous tissue problem caused by its high dose, but later tolerated.

The extract did not adversely affect food intake in both sexes of the rats at all doses, and had no harmful effect on body growth patterns. The transitional body weight decrement observed at the dose of $2000 \mathrm{mg} / \mathrm{kg}$ body weight during the $2^{\text {nd }}$ and $3^{\text {rd }}$ weeks might be due to physiological variation in food intake and metabolism. During the later weeks, there were progressive body weight gains in all groups of rats of both sexes over the whole period of the experiment. This is in line with Ghebressilase et al. (7) who reported a progressive non-significant body weight increment with no significant changes between male and female rats that received $600,750,900$ and $1500 \mathrm{mg} / \mathrm{kg}$ of $M$. stenopetala extract for 6 weeks.

Evaluation of changes in organ weight between experimental and control animals in toxicological studies is an important indicator of toxicity (15). In the present study, there was no significant change in both liver and kidney weight in the animals that received the extract at all doses when compared to the controls. This finding is again in line with the previous subchronic study of Ghebressilase et al. (7) and suggest for non-toxic effect of the extract on the organs studied to be manifested by weight change.

Investigations on blood could serve as a diagnostic index of pathological, toxicological and physiological status of animals. Blood profile usually provides important information on the response of the body to injury or lesion, deprivation and stress (16). Therefore, it is one of the most sensitive targets for toxic compounds (17). In this study, hematological parameters were evaluated to obtain any toxicity related information that may not be detected by gross examinations and assessment of organs and body weight.

In the present study, administration of the extract at all studied doses did not cause significant changes in the total red blood cells count, HGB, HCT and
MCVC in both sexes, although there was a significant decrement of $\mathrm{MCH}$ in male rats that received 1000 and $2000 \mathrm{mg} / \mathrm{kg}$ body weight. In addition, there was increment in the MCV values in female rats treated with the extract at all the three doses. This is in agreement with the findings of Adedapo et al. (18) which showed increased MCV and decreased $\mathrm{MCH}$ in rats that received 1600 and $2000 \mathrm{mg} / \mathrm{kg}$ body weight for three weeks. The observed changes in the values of $\mathrm{MCV}$ and $\mathrm{MCH}$ might be attributed to the defect in nuclear maturation, as seen in megaloblastic anemia due to foliate or B12 deficiency, resulting in large oval erythrocytes $(19,20)$. This may indicate that exposure to high dose of the extract for a longer period of time may somehow affect the intrinsic factors in the stomach and reduce the absorption of vitamin B12.

In the present study, unlike in the female rats, significant increments were observed in the male rats treated with the extract in the levels of ALP at $2000 \mathrm{mg} / \mathrm{kg}$ body weight dose as well as AST and ALT at 1000 and $2000 \mathrm{mg} / \mathrm{kg}$ body weight doses as compared to the controls. These observations are in line with those of other previous acute and subchronic studies of Adedapo et al. (18), Ajibade et al. (21) and Geleta et al. (22). Such findings might suggest that the extract has mild hepatotoxic effect in male rats. Indeed, histopathological findings of male rats in this study also suggest for a mild sign of hepatotoxicity in the rats treated at the higher doses. This may show that male rats are sensitive while female rats are resistant to the hepatoxic effect of phytochemicals present in $M$. stenopetala, resulting from the absence of isoform of cytochrome P450 involved in the bio-activation of alkaloid in female rats as previously suggested (23).

Chronic treatment with the extract did not significantly affect urea and creatinine levels in male rats at all doses and 500 and $1000 \mathrm{mg} / \mathrm{kg}$ in female rats, while at dose of $2000 \mathrm{mg} / \mathrm{kg}$, it significantly decreased urea and increased creatinine levels in female rats. The occurrence of significantly decreased urea and increased creatinine levels only in the female rats treated with the extract at $2000 \mathrm{mg} / \mathrm{kg}$ dose is interesting, but may suggest for the presence of mild nephrotoxicity in female rats. In line with this,

DOI: http://dx.doi.org/10.4314/ejhs.v30i2.14 
previously, it was suggested that female rats are often more sensitive to nephrotoxic compounds than males $(11,24)$.

Histological examination of liver sections of male rats treated with the extract of M. stenopetala revealed sign of mild toxicity at the higher doses, while at the lower dose, the normal architecture of the liver was not disturbed. In the male rats treated with 1000 and $2000 \mathrm{mg} / \mathrm{kg}$ body weight, there was intrahepatic and extra hepatic bile retention. Moreover, around the central veins and portal triads, there were some mononuclear leukocytic cells infiltration, congestion of sinusoids, cytoplasmic vacuolization's of hepatocytes, and hydropic changes. These findings are comparable to that of a previous acute study by Ajibade et al. (21) where oral administration of a related plant, M. olifera at 800 and $1600 \mathrm{mg} / \mathrm{kg}$ body weight induced portal cellular infiltration, periportal congestion and hydropic degeneration of hepatocytes in the liver.

In the present study, histological evaluation of sections of the kidneys from rats treated with the extract did not show any sign of toxicity, except in those female rats treated at the highest dose. In the female rats which received the extract at the dose of $2000 \mathrm{mg} / \mathrm{kg}$, there were minor tubulointerstitial leukocytic infiltration, wider urinary space and congested glomeruli in some areas of both cortex and medulla of the kidney sections. These findings are in line with a study by Ajibade et al. (21) where cortical congestion and interstitial hemorrhages in the kidneys of rats following treatment of $M$. olifera at doses of 600,900 and $2000 \mathrm{mg} / \mathrm{kg}$ body weight were reported. The histological changes observed in the present study may also be related with the observed changes in the values of urea and creatinine at dose of $2000 \mathrm{mg} / \mathrm{kg}$ body weight in the female rats, and may be indicative of mild nephrotoxicity.

In conclusion, the findings from the present study suggest that prolonged administration of the aqueous leaves extract of $M$. stenopetala in rats at lower doses of administration is safe. However, at a higher dose, it might show mild toxicity with differential sensitivity between the two sexes.

\section{REFERENCES}

1. Abuye, C., Urga, K., Knapp, H., Selmar, D., Omwega, A.M., Imungi, J.K. and Winterhalter, P. A compositional Study of Moringa Stenopetala leaves. East African Medical Journal2003; 80 (5): 247-252.

2. Orwa, C. A. Mutua, K. R, Jamnadass, R. and Anthony, S. Agro forestry Database: a tree reference and selection guide version 2009;4.0; 1-5.

3. Padayachee, B. and Baijnath,H. An overview of the medicinal importance of Moringaceae. Journal of Medicinal Plants Research 2012; Vol. 6(48): pp. 5831-5839.

4. Anwar, F. Latif, S. Ashraf, M. Gilan, A. Moringa oleifera food plant with multiple medicinal uses; Physiotherapy Research, 2007; 21: 17-25.

5. Ghosh, N. Anti-Proliferative effect of the Moringa oleifera Leaf extract on Human Cancer Cell ,International conference on "Molecular Biology and its applications" at Department of Life Science and Biotechnology, Jadavpur University, Kolkata , 2014.

6. Mengistu M, Abebe Y, Mekonnen Y, Tolessa $\mathrm{T}$. In vivo and In vitro hypotensive effect of aqueous extract of Moringa stenopetala leaves. Afr. Health Sci.2012; 12(4):445-51.

7. Ghebreselassie D, Mekonnen Y, Gebru G, Ergete W, Huruy K. The effects ofMoringa stenopetala on blood parameters and histopathology of liver andkidney in mice. Ethiop J Health Dev. 2011; 25:51-7.

8. Musa, A., Vata, B. and Debella, A. Acute toxicity studies of butanol fraction of leaves of Moringa stenopetala in rats. Asian Pac. J. Health Sci. 2015; 2(2): 160-164.

9. Toma, A., Makonnen, E., Mekonnen, Y., Debella, A. and Adisakwatana, S. Antidiabetic activities of aqueous ethanol and n-butanol fraction of Moringa stenopetala leave in streptozotocin-induced diabetic rats. Asian Pac J. Trop. Biomed. 2012; pp. 2-8.

10. Debella, A. Manual for phytochemical screening of medicinal plants.Department of

DOI: http://dx.doi.org/10.4314/ejhs.v30i2.14 
Drug Research, EHNRI, Addis Ababa, Ethiopia, 2002; pp. 1-55.

11. OECD Guidelines for the testing of chemicals. Sub chronic and chronic Oral Toxicity - Upand-Down-Procedure (UDP) 2009; No. 452.

12. WHO. General guidelines for methodologies on research and evaluation of traditional medicine Geneva: World Health Organization; 2000. (WHO/EDM/TRM/2000.1).

13. Kilkenny C, Browne WJ, Cuthill IC, Emerson $\mathrm{M}$, Altman DG. Improving Bioscience Research Reporting: The ARRIVE Guidelines for Reporting Animal Research. PLOS Biol. 2010; 8(6): e1000412. doi:10.1371/journal.pbio.1000412.

14. Dapar, L. P. Maxwell, Aguiyi, C. John , Wannang, N. Noel, Gyang, S. Steven and Tanko, M. Naanlep. The histopathological effects of Securidacalonge pedunculata on heart, liver, kidney and lungs of rats, 2007.

15. Sellers RS, Morton D, Michael B, Roome N, Johnson JK, Yano BL, Perry R, Schafer K. Society of Toxicologic Pathology position paper: organ weight recommendations for toxicology studies. J.Toxicol Pathol.2007; 35, 751-755.

16. Adeneye AA, Benebo AS. Pharmacological evaluation of a Nigerian polyherbal health tonic tea in rat. Africa Journal of Biomedical research2007; 10: 249-255.

17. Nancy Everds (. Interpretation of hematology data on Toxicology studies. 2008; Amegen Inc. Seattle, PA.

18. Adedapo AA, Mogbojuri OM and Emikpe BO. Safety evaluations of the aqueous extract of the leaves of Moringa oleifera in rats,
Journal of Medicinal Plants Research2009; 3(8):586-591.

19. Asare, G.A., B. Gyan, K. Bugyei, B. Adjei, R. Mahama, P. Addo. Toxicity potentials of the nutraceutical Moringa oleifera at suprasupplementation levels. J. Ethnopharmacol.2012; 139: 265-272.

20. Olayemi, A.T., M.J. Olanrewaju and Oloruntoba A.C. Toxicological evaluation of Moringa oleifera Lam seeds and leaves in Wistar rats. Pharmacogn. Commn.2016; 6: 100-111.

21. Ajibade TO.,Olayemi FO. and Arowolo RO. The haematological and biochemical effects of methanol extract of the seeds of Moringa oleifera in rats. 2011; University of Ibadan, Ibadan, Nigeria.

22. Geleta B, Makonnen E and Debella A. Toxicological Evaluations of the Crude Extracts and Fractions of Moringa stenopetalaleaves in Liver and Kidney of Rats. J Cytol Histol. 2016; 7: 383.

23. Williams DE, Reed RL, Kedzierski B, Dannan GA, Guengerich FP. Bio-activation and detoxication of the pyrrolizidine alkaloid senecionine by cytochrome P-450 enzymes in rat liver. Drug Metab Dispos 1989; 17: 387392.

24. Zebinden, G., K. Fent and M. H. Thouin Nephrotoxicity screening in rats; general approach and establishment of test criteria, Arc. Toxicol.1988; 61, 344-348. 